\title{
RISING RATE OF CESAREAN SECTION - A YEAR REVIEW.
}

\author{
Shanti Subedi
}

\begin{abstract}
:
Caesarean section is one of the most common surgeries performed in modern obstetrics. The rising trend of caesarean section in modern obstetrics is a major concern in health care system all over the world. With all the limited health care resources in a developing country like Nepal, this rising trend definitely has major implication. Rates of caesarean section countries in many countries have increased beyond the recommended level (WHO, 1985). Current available data from developed countries revealed morbidity and mortality from CS is more than in vaginal delivery for both the mother and fetus. Thus this study was conducted to evaluate the rate and indication for CS and to identify the measures to decrease its incidence if possible. Our results shows the foetal distress as the most common indication for Cesarean section in a eastern part of Nepal, which can be minimized significantly if a proper and timly investigation is carried out.
\end{abstract}

Key words: Caesarean Delivery, Indications, CS audit.

\section{Introduction:}

Caesarean section is one of the most common surgeries performed in modern obstetrics. Originally performed in interest of the mother, is now frequently done for foetal indication. Though it was introduced in clinical practice as a life saving procedure both for the mother and the baby. As other procedures of some complexity, its use follow $\mathrm{s}$ the health care inequity pattern of the world, underuse in low income setting, and adequate or even unnecessary use in middle and high income setting ${ }^{1 .}$

Developing countries like Nepal are faced to the challenge of making the best use possible of limited resources to improve the health of women and children. Obstetrical intervention should be evidence based as mortality and morbidity due to unnecessary intervention could be hazardous.

The rising trend of caesarean section in modern obstetrics is a major concern in health care system all over the world ${ }^{2}$. With all the limited health care resources in a developing country like Nepal, this rising trend definitely has major implication. According to $\mathrm{WHO}$, rates of caesarean section in many countries have increased beyond the recommended level of $15 \%^{3}$, almost doubling in the last decade especially in high income areas like Australia, France, Germany, Italy, North America and United Kingdom $^{4,5,6,7}$. Similar trend is also seen in low resource countries like China, Brazil and India, especially due to births in private hospitals. Eventhough the indication of CS have not changed so far and these remain foetal distress, malpresentation, multiple gestation, previous caesarean, protracted labour and CS on demand. Current available data from developed countries revealed morbidity and mortality from CS is more than in vaginal delivery for both the mother and fetus. Thus this study was conducted to evaluate the rate and indication for CS and to identify the measures to decrease its incidence if possible. 
Original Article

\section{Material and Methods:}

This study was carried out in the department of Obstetrics and Gynaecology, Nobel Medical College, Biratnagar, with the aim to analyze the rate and indications for caesarean section. This study also aimed to provide a recommendation for health care professionals which may likely to reduce the rising trend of caesarean section as much as possible. With the objective to fulfil the aforementioned aims, this study was carried out in September 2010 to September 2011. All consecutive patients admitted to the Obstetrics and Gynaecology ward of Nobel Medical College, with history of pregnancy and labor pain, were included in the study.
Cesarean Section

Their demographic details of the patient were recorded including age, parity, address, socioeconomic status, period of gestation, stage of labour and fetal condition.

\section{Results:}

A total of 2011 deliveries were conducted in one year, out of which 1560(77.57\%) were vaginal,400(19.89\%) caesarean and 51 $(2.53 \%)$ instrumental deliveries (Table 1).Regarding booking status of the patients, it was very low as most of the cases were referred from periphery and government hospital. (Table 2) The various indications of CS were shown in Table 5.

Table: 1: Incidence:

\begin{tabular}{|c|c|}
\hline Total Deliveries & 2011 \\
\hline Vaginal & 1560 \\
\hline Instrumental & 51 \\
\hline Caesarean & 400 \\
\hline
\end{tabular}

Table 2: Booking Status of the patients

\begin{tabular}{|c|c|}
\hline Booked & 40 \\
\hline Uunbooked & 1971 \\
\hline
\end{tabular}

Table 3: Gravidity Status of the Patients

\begin{tabular}{|c|c|}
\hline Primigravida & 1400 \\
\hline Multigravida & 540 \\
\hline Grandmultigravida & 71 \\
\hline
\end{tabular}


Table 4: Types of Cesarean Section

\begin{tabular}{|c|c|}
\hline Primary & 1926 \\
\hline Repeat & 85 \\
\hline
\end{tabular}

\section{Table 5: Indications of Cesarean Section}

\section{$\underline{\text { Indication }}$}

1. Foetal distress

2. Previous caesarean

3. Failed induction

4. Non-progress of labour

5. Breech presentation

6. Cephalopelvic disproportion

7. Preeclampsia and eclampsia

8. Ante partum haemorrhage

9. Severe Oligohydramnios

10. Multiple pregnancy

11. Obstructed labour

12. Uterine rupture

13. Cord prolapse

14. Caesarean on Demand

\section{Discussion:}

In this study the total number of deliveries was 2011 and of which $400(19.89 \%)$ was caesarean deliveries. Increased caesarean rate is a major health concern worldwide, which has increased from 5-7\% in 1970 to $25-30 \%$ in

$2003^{8 .}$ Increased rate in developed countries is due to health insurance system, fear of litigation, on demand, extensive use of foetal monitoring. But it is not the rule in our set up as the patients are not given the autonomy of decision making and the health personnel play the key role in patient's decision. Being

a public sector hospital, where safe

$$
\begin{aligned}
& 105(26.25 \%) \\
& 85(21.25 \%) \\
& 45(11.25 \%) \\
& 40(10 \%) \\
& 40(10 \%) \\
& 16(4 \%) \\
& 15(3.75 \%) \\
& 13(3.25 \%) \\
& 10(2.5 \%) \\
& 10(2.5 \%) \\
& 6(1.5 \%) \\
& 5(1.25 \%) \\
& 5(1.25 \%) \\
& 5(1.25 \%)
\end{aligned}
$$$$
\text { Number (Percentage) }
$$

motherhood programme is implicated it caters a population of low and middle socio-economic class. Our study revealed a CS rate of $(19.89 \%)$ which is comparable to the rates in different centres like Raipur, India (26.2\%), and other South-East Asian countries like The Philippines (22.7\%), Malaysia (19.1\%), Indonesia $(29.6 \%)^{9,10}$. Another study done in tertiary referral centre in Eastern Nepal, BPKIHS revealed a rate of $28.6 \%$ in 2006 and $33.7 \%$ in $2007^{11}$. The high CS rate in this hospital may be partially attributed to the fact that this being a referral hospital and it has been hypothesized that increased CS rate may be due to the procedure being performed at a lower threshold of abnormality detection among the 


\section{Original Article}

health care providers ${ }^{12 .}$ The most common indication for CS in our set up was for foetal distress $(26.25 \%)$. The gold standard method of estimation of foetal distress is not done in our set up and what we have for foetal monitoring is only cardiotocography.CTG is known to overestimate the foetal distress. Many gestational and antepartum factors are known to influence the foetal response in a CTG.The accurate method of estimation of foetal distress is foetal scalp $\mathrm{pH}$ estimation ${ }^{13 .}$

In our study, another common indication was previous CS $(21.25 \%)$, which is the most common indication worldwide. Enkin et al analyzed a series of 8899 women who were permitted for trial of labour out of them $20.1 \%$ were delivered by caesarean section and $79.9 \%$ were delivered vaginally ${ }^{14}$. The reluctance to permit a trial of labour after previous CS is probably due to either the obstetrician considering that a repeat $\mathrm{CS}$ is much safer and convenient and is less likely to give rise to the complication and possible subsequent litigation or due to maternal preference. In our setup no trial was given even after one previous Cs until and unless women comes in second stage of labour and this is the cause for increased rate for previous CS and failure to conduct VBAC in our hospital was due to lack of trained human resources. Another study done by McMahon et al reported that that higher rates of maternal and foetal morbidity exist with VBAC as compared to repeat $\mathrm{CS}^{15}$. However study done by Gonen found that VBAC with

\section{References:}

1. Luz Gibbons et al. The Global Numbers and costs of Additionally Needed and Unnecessary Caesarean Sections Performed Per Year: Overuse as a Barrier to Universal Coverage. World Health Report (2010)

\section{Caesarean sections. Postnote No. 184. London:} Parliamentary Office of Science and Technology; 2002. Available from: http://www.parliament.uk /post/pn184.pdf.

\section{Cesarean Section}

a well defined protocol was safe as compared to repeat $\mathrm{CS}^{16}$.

Failed induction and non-progress of labour were the next frequent indications. Judicious use of oxytocics and the use of partograph are definitely beneficial to reduce the CS rate. Breech presentation accounting for $10 \%$ of CS. Though ECV (external cephalic version) has been suggested as an intervention to reduce high CS rate at 37 wks gestation but it has its own drawbacks and requires skill. A meta-analysis showed significantly lower rates of perinatal mortality and neonatal morbidity with planned caesarean section than with planned vaginal birth ${ }^{17}$.On demand CS rate being $1.25 \%$ in our set up. In West countries it is high and comprises of around $23 \%-38.9 \%$ in the United Kingdom $^{18 .}$

This trend is also partly due to some evidence that suggests that planned caesarean birth might protect against urinary and faecal incontinence, pelvic organ prolapse and sexual dissatisfaction, further increasing its appea $^{19 .}$

\section{Conclusion:}

The trend in performing caesarean section is increasing and the most common indication for Cesarean section is foetal distress and we should be more investigational to diagnose it as many of the cases didn't have any evidence of it intrapartum.

3. World Health Organization. Appropriate technology for birth. Lancet 1985; 2(8452):436-7.

4. C Black, JA Kaye, H Jick. Caesarean delivery in the United Kingdom: time trends in the general practice research database Obstet Gynecol 2005; 106 : 151-5.

5. Laws, PJ, Sullivan EA. Australia's mothers and 


\section{Original Article}

babies 2002. Perinatal Statistics Series No. 15. Sydney: National Perinatal Statistics Unit; 2004

6. AL Tranquilli, SR Giannubilo. Cesarean delivery on maternal request in Italy. Int J Gynaecol Obstet 2004; 84: 169-70.

7. $\mathbf{R}$ Dobson. Caesarean section rate in England and Wales hits 21\%. BMJ 2001; 323:951

8. Leitch CR.Walkers JJ. Cesarean section rates.BMJ1994; 308:133-4.

9. Singh Abha and Channawar Reema. A recent way of evaluating caesarean birth. J Obstet Gynecol IndiaVol. 59, No. 6: November/December 2009 pg 547-51.

10. Mario R Festin, Malinee Laopaiboon, Porjai Pattanittum, Melissa $\mathbf{R}$ Ewens, David J Henderson-Smart, Caroline A Crowther. Caesarean section in four South East Asian countries: reasons for, rates, associated care practices and health outcomes.BMC Pregnancy and Childbirth 2009, 9:17

11. S. Chhetri et al. Cesarean Section: its rates and indications at a tertiary referral center in Eastern Nepal.2011 September-December 2011; Vol 9(3):179-83

12. S. N. Mukherjee. Rising caesarean rate.J. Obstet Gynecol India 2006; (56)4:298-300.

\section{Cesarean Section}

13. Unnikrishanan B, Rakshith Prasad B et al. Trends and Indication for Caesarean Section in a tertiary Obstetric Hospital in Coastal South India. AMJ 2010; (821-825)

14. Enkin M. Labour and delivery following previous caesarean section. In Enkin M, Keirs MJ,Chalmers I (eds). Elective Care in Pregnancy and Childbirth, pp 1196-1215. Oxford: Oxford University Press, 1989.

15. Mc Mahon MJ, Luther ER, Bowes WA Jr, Olshan AF. Comparison of a trial of labor with an elective second caesarean section. $\mathrm{N}$ England $\mathrm{J}$ Med1996; 335(10):689-

16. Gonen R, Tamir A, Degani $\mathbf{S}$ et al. Variables associated with successful vaginal birth after one caesarean section: a proposed vaginal birth after Caesarean section score. Am J Perinatol2004; $21: 447-53$

17. Hannah M, Hannah W. Caesarean section or vaginal birth for breech presentation at term.BMJ1996; 312:1433-1434

18. Wilkinson C, McIlwaine G, Boulton-Jones C,Cole S. Is a rising caesarean section rate inevitable?Br J Obstet Gynaecol.1998;105(1):45-52.

19. Hemminki E, Merilainen J. Long-term effects of caesarean sections: Ectopic pregnancies and Placental problems. Am J Obstet Gynecol 1996; 174: 1569 -1574 .

Correspondence address: Shanti Subedi, Lecturer, Department of Obstetrics and Gynaecology, NMCTH, Biratnagar. Phone no. 9842021806. E-mail: drshantisubedi@yahoo.com 